\title{
THE BEAUTY OF FAILURE: HAMARTIA IN ARISTOTLE'S POETICS*
}

\begin{abstract}
In Poetics 13, Aristotle claims that the protagonist in the most beautiful tragedies comes to ruin through some kind of 'failure'-in Greek, $\dot{\alpha} \mu \alpha \rho \tau i \alpha$. There has been notorious disagreement among scholars about the moral responsibility involved in $\alpha \mu \alpha \rho \tau i \alpha$. This article defends the old reading of $\dot{\alpha} \mu \alpha \rho \tau i \alpha$ as a character flaw, but with an important modification: rather than explaining the hero's weakness as general weakness of will

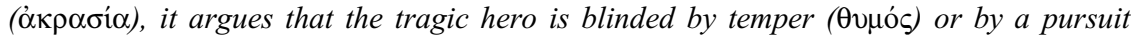
for fine, good and desirable things - that is, by what may be labelled 'qualified' weakness of will. The upshot is that $\alpha \mu \alpha \rho \tau i \alpha$ ends up as being less blameworthy than 'proper'

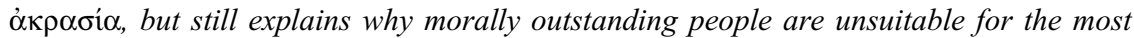
beautiful tragedies.
\end{abstract}

Keywords: Aristotle; Poetics; hamartia; akrasia; thumos; Oedipus

Few lines in Greek philosophy have caused more sustained controversy than the famous $\dot{\alpha} \mu \alpha \rho \tau i \alpha$ passage in Aristotle's Poetics (1453a7-22). ${ }^{1}$ Aristotle here states that the most beautiful tragedies concern a person who is neither morally outstanding nor wicked. Tragedy should imitate a person who falls between these two extremes and comes to ruin through some kind of 'failure'-in Greek, $\dot{\alpha} \mu \alpha \rho \tau i \alpha$. The notion may denote a wide range of failures, spanning moral wickedness to innocent mistakes, and the problem thus arises: what kind of failure does Aristotle have in mind for the best tragic plot?

After much heated debate throughout the last century and a half, most modern scholars view $\dot{\alpha} \mu \alpha \rho \tau i \alpha$ as an error of judgement for which the tragic hero cannot be blamed. Still others claim that $\alpha \mu \alpha \rho \tau i \alpha$ refers to a range of failures, so that it is up to the poet to decide how the hero comes to ruin. Another, currently less widespread, interpretation is that $\alpha \mu \alpha \rho \tau i \alpha$ is linked to a flaw in the hero's moral character and that he is at least partially responsible for his misfortune. ${ }^{2}$ Modern critics are often quick to dismiss this view: a character flaw, they object, would lessen the moral quality

* This article has been a number of years in gestation, and in that time accrued many debts. I thank especially Franco Trivigno, Karen Margrethe Nielsen, Hallvard Fossheim, Øyvind Rabbås and Eyjólfur Kjalar Emilsson, in addition to $C Q$ 's anonymous referee and editor.

${ }^{1}$ Henceforth all references to Aristotle not preceded by the name of a work are to the Poetics. I am quoting Kassel's edition (Oxford, 1966) and Halliwell's translation (Cambridge, MA and London, 1995), with some emendations by me. For the Nicomachean Ethics (= Eth. Nic.), I quote Bywater's edition (Oxford, 1894) and Rowe's translation (Oxford, 2002).

${ }^{2}$ Part 2 of the article returns to a detailed exposition of the literature. Among the works influential in shaping the three main interpretations are J.M. Bremer, Hamartia: Tragic Error in the Poetics of Aristotle and in Greek Tragedy (Amsterdam, 1969); T.C.W. Stinton, 'Hamartia in Aristotle and Greek tragedy', CQ 25 (1975), 221-54 (= id., Collected Papers on Greek Tragedy [Oxford], 14385); and P.W. Harsh, 'Hamartia again', TAPhA 76 (1945), 47-60.

(C) The Author(s), 2021. Published by Cambridge University Press on behalf of The Classical Association. This is an Open Access article, distributed under the terms of the Creative Commons Attribution licence (http://creativecommons.org/licenses/by/4.0/), which permits unrestricted re-use, distribution, and reproduction in any medium, provided the original work is properly cited. 
of the hero and make him unfit for tragedy. ${ }^{3}$ In this paper, I set out to prove that this belief is mistaken. By drawing on Aristotle's ethics, I defend the old reading of $\dot{\alpha} \mu \alpha \rho \tau i \alpha$ as a character flaw, but with an important modification: rather than explaining

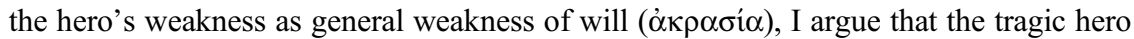
is blinded by temper $(\theta v \mu$ ó $\varsigma$ ) or by a pursuit for fine, good and desirable things - that is, by what may be labelled 'qualified' weakness of will. The upshot is that $\alpha \mu \alpha \rho \tau i \alpha$ ends up as being less blameworthy than 'proper' $\alpha \kappa \rho \alpha \sigma i \alpha$, but still explains why morally outstanding people are unsuitable for the most beautiful tragedies. This, I hope, should be reason enough to bring up the well-known issue of $\dot{\alpha} \mu \alpha \rho \tau i \alpha$ once again.

The structure of the paper is as follows: part 1 explains the problem of understanding $\dot{\alpha} \mu \alpha \rho \tau i \alpha$, while part 2 assesses how previous critics have defined the notion. Part 3 argues that $\dot{\alpha} \mu \alpha \rho \tau i \alpha$ is better understood as a weakness in the hero's moral character on grounds of the Poetics alone. It then brings in the Nicomachean Ethics and attempts to demonstrate that it provides us with a sound basis for understanding how a moral weakness may give rise to ignorance and cause a shift from fortune to misfortune without rendering the hero too wicked for tragedy. Part 4 spells out my redefinition of $\dot{\alpha} \mu \alpha \rho \tau$ ti $\alpha$.

\section{THE PROBLEM}

The problem arises in chapter 13, where Aristotle turns to the requirements the plot has to meet to satisfy the formerly established claims for tragedy. He starts by eliminating the chains of events that are unsuitable for the finest tragedies:

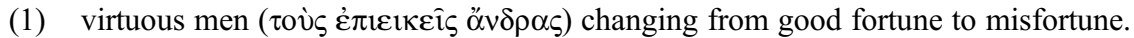

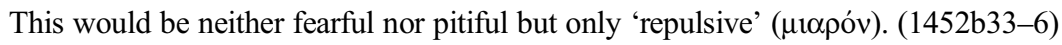

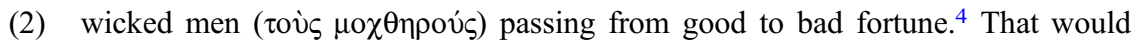
be the 'most untragic of all', as it would be neither appealing to our human compassion, nor pitiful, nor fearful. (1452b36-1453a1)

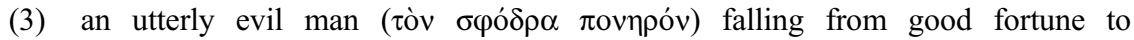
misfortune. Although this pattern might be appealing, it would not arouse pity or fear. (1453a1-7)

Two comments are worth making here. First, Aristotle's use of غ̇лıєкńs is peculiar. It often means 'decent' or 'respectable', which suggests that someone is good overall but

${ }^{3}$ E.g. H. Kim, 'Aristotle's hamartia reconsidered', HSPh 105 (2010), 33-52, at 40, 49-50; M. Husain, Ontology and the Art of Tragedy: An Approach to Aristotle's Poetics (Albany, 2002), 89; R. Hull, 'Hamartia and heroic nobility in Oedipus Rex', Ph\&Lit 17 (1993), 286-94, at 288; E.S. Belfiore, Tragic Pleasures: Aristotle on Plot and Emotion (Princeton, 1992), 168; M. Cyzyk, 'Hamartia, akrasia, ignorance, and blame in Aristotle's philosophy', Kinesis 18 (1990), 17-35, at 20; Bremer (n. 2), 62; O.B. Hardison, 'Commentary', in Aristotle's Poetics (Englewood Cliffs, NJ, 1968), 55-280, at 183-4; L.J. Potts, Aristotle on the Art of Fiction (London, 1968), 81; P. van Braam, 'Aristotle's use of hamartia', CQ 6 (1912), 266-72, at 271-2. Cf. R.D. Dawe, 'Some reflections on ate and hamartia', HSPh 72 (1968), 89-123 (= id., Corruption and Correction. A Collection of Articles [Amsterdam, 2007], 81-112), at 89-90: 'There still flourishes, even in otherwise civilised parts of the globe, the belief that hamartia may mean a flaw of character ... The question whether hamartia may or may not mean a flaw of character is one no longer open to discussion; for this interpretation, which had already been challenged by P. van Braam in $C Q 1912$ p. 266, was killed stone dead by Hey in Philologus 1928 ...'.

${ }^{4}$ Following D.W. Lucas, Aristotle: Poetics (Oxford, 1968), I do not consider the nuances between $\dot{\alpha} \tau v \chi i \alpha$ ('bad fortune') and $\delta v \sigma \tau \chi \chi i \alpha$ ('misfortune') to be of decisive significance for the interpretation of $\alpha \mu \alpha \rho \tau i \alpha$. I later use 'bad fortune', 'adversity' and 'misfortune' interchangeably. 
not necessarily perfect. There are, however, good reasons for taking غ̇лıєıкं́ to mean 'virtuous' in this context: shortly after, Aristotle refers back to the غ̇ $\pi \varepsilon \iota \kappa n$ ' when reminding the reader that the tragic hero is not 'pre-eminent in virtue and justice' (1453a8) and that he does not come to ruin 'because of vice and depravity' but because of some kind of $\dot{\alpha} \mu \alpha \rho \tau i \alpha(1453 \mathrm{a} 8-10)$. The $\dot{\varepsilon} \pi \varepsilon 1 \kappa \eta \dot{\zeta}$, then, appears to be a person who excels in virtue and righteousness. This is compatible with Eth. Nic. 9.8, where Aristotle writes that the غ̇лıєкńs does what he should 'since every intelligence chooses what is best for itself, and the غ̇ंıııń person obeys commands of intelligence' (Eth. Nic.

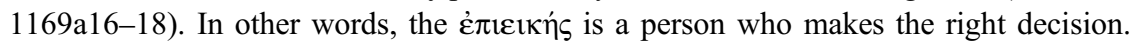

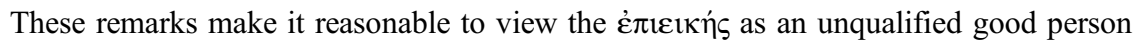
in Poetics 13; if the غ̇лıєıń ऽ were equal to the overall good (but still fallible) man, there would be no distinguishable mark between the غ́лıєıńs and the so-called middle character (whom Aristotle prefers and who will be treated in detail soon), and the proper tragic plot which he later lays forth would be just as repulsive. Hence the ideal protagonist should implicitly not be understood as a perfectly flawless person, and there appears to be no better option than reading غ̇лııкńs as 'virtuous'. 5

Second, it is important to have Aristotle's definitions of pity and fear in mind to understand why a wicked or evil person would be unsuitable. While pity concerns

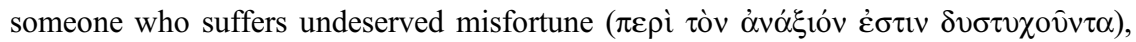

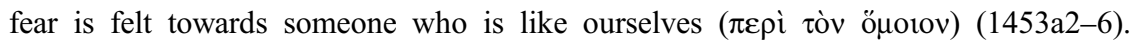
A thoroughly bad person would obviously not suffer undeservedly, and would not be a person similar to the average person. Hence, this kind of person does not qualify as a protagonist of tragic poetry.

Aristotle then lays forth the preferred chain of events for the successful tragedy (1453a7-22):

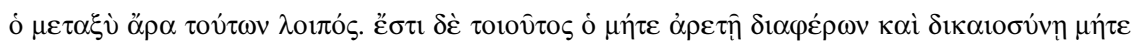

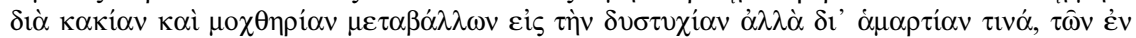

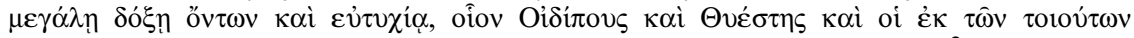

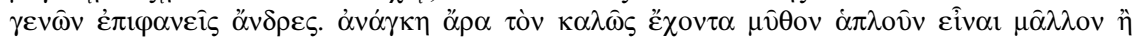

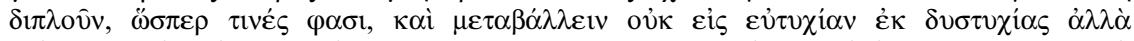

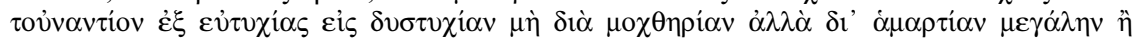

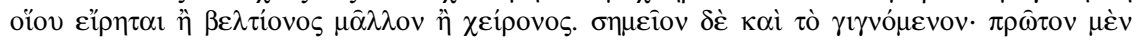

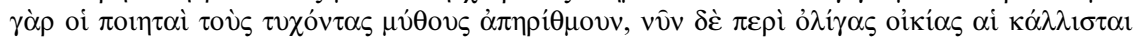

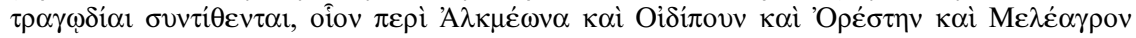

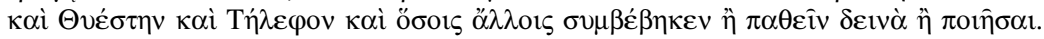

This leaves, then, the person in-between these cases. Such a person is someone not pre-eminent in virtue and justice, and one who falls into adversity not through vice and depravity but through some $\dot{\alpha} \mu \alpha \rho \tau i \alpha$; and one belonging to the class of those who enjoy great renown and prosperity, such as Oedipus, Thyestes and eminent men from such lineages. The well-made plot, then, ought to be single rather than double, as some maintain, with a change not to prosperity from adversity, but on the contrary from prosperity to adversity, caused not by depravity but by a great $\alpha \mu \alpha \rho \tau i \alpha$ of a character either like that stated, or better rather than worse. (Actual practice too points to this. Originally, the poets recounted any and every story, but nowadays the finest tragedies are composed about only a few families, such as Alcmaeon, Oedipus, Orestes, Meleager, Thyestes, Telephus and many others as have happened to suffer or perpetrate terrible things.)

\footnotetext{
${ }^{5}$ This translation follows S.H. Butcher, Aristotle's Theory of Poetry and Fine Art (New York, $1951^{4}$ ).
} 
The central question now arises: how are we to understand $\alpha \mu \alpha \rho \tau i \alpha$ ? The noun may in principle denote a wide range of failures, spanning from moral wickedness to an innocent missing of the mark. It is clear that $\dot{\alpha} \mu \alpha \rho \tau i \alpha$ causes fortune to make a shift; but what kind of failure does Aristotle more specifically have in mind? Let us start with an account of the modern debate.

\section{READINGS OF POET. 1453A7-22}

In what follows, I classify the secondary literature into three categories: readings that link the notion with (a) ignorance for which one can be held morally responsible, (b) ignorance for which one cannot be held morally responsible and (c) various failures, both voluntary and involuntary. ${ }^{6}$ I name (c) 'open' readings. ${ }^{7}$

\section{a. Blameworthy ignorance views}

Aristotle's dismissal of the virtuous as unsuitable for the tragic plot is central to interpretations of $\dot{\alpha} \mu \alpha \rho \tau i \alpha$ as a failure for which one can be held morally responsible. While some of these readings define $\dot{\alpha} \mu \alpha \rho \tau i \alpha$ as a 'character flaw' that resides within the agent, others view it as a concrete action that is morally blameworthy. ${ }^{8}$ As the arguments for and against these readings are very much overlapping, I treat them under one heading and point out the differences only when relevant. Common to both readings is that they view $\alpha \mu \alpha \rho \tau i \alpha$ as a failure that reflects the moral imperfection of the protagonist and, importantly, causes him to be ignorant in a morally blameworthy manner. Both of them have been criticized for making the protagonist worse than what Aristotle allows for. ${ }^{9}$

\footnotetext{
${ }^{6}$ Following S.S. Meyer, Aristotle on Moral Responsibility (Oxford, 1993), I take what Aristotle defines as the limit of voluntariness to be the limit of moral responsibility. Thus, when writing 'morally responsible', I refer to voluntary actions and, when writing 'not morally responsible', I refer to involuntary actions that may be excused. Voluntary actions are further open to praise or blame (Eth. Nic. 1109b30-1); when later using the label 'blameworthy', I apply this only to voluntary actions.

${ }^{7}$ Some interpreters have turned to Aristotle's definition of $\alpha \mu \alpha \dot{\alpha} \rho \tau \eta \mu \alpha$ in Eth. Nic. 5.8 (1135b1719) to account for $\dot{\alpha} \mu \alpha \rho \tau$ tí $\alpha$ in Poetics 13. But this definition does not help us solve the problem; as R. Sorabji, Necessity, Cause and Blame (Ithaca, NY, 1980), 295-8 argues, we cannot use this definition to infer what $\dot{\alpha} \mu \alpha \rho \tau i \alpha$ means in the Poetics because Aristotle uses $\dot{\alpha} \mu \alpha \dot{\alpha} \rho \tau \eta \mu \alpha$ both in a generic and in a specific sense in Eth. Nic. 5.8. The former sense covers different ways in which a person may inflict harm unknowingly, which makes it impossible to restrict $\dot{\alpha} \mu \alpha \dot{\alpha} \rho \tau \eta \mu \alpha$ to having

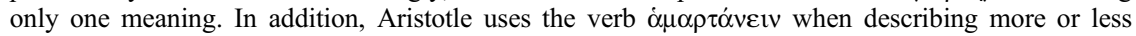
culpable ways of inflicting harm $(1135 \mathrm{~b} 18,1135 \mathrm{~b} 22-3,1136 \mathrm{a} 7)$, which makes it even harder to use Eth. Nic. 5.8 to settle on what $\dot{\alpha} \mu \alpha \rho \tau i$ means in Poetics 13.

${ }^{8}$ Harsh (n. 2) and G.K. Gresseth, 'The system of Aristotle's Poetics', TAPhA 89 (1958), 312-35 defend the former, while S. Østerud, 'Hamartia in Aristotle and Greek tragedy', SO 51 (1976), 65-80, V. Cessi, Erkennen und Handeln in der Theorie des Tragischen bei Aristoteles (Frankfurt am Main, 1987) and A. Schmitt, Aristoteles: Poetik (Darmstadt, 2008) defend the latter. I return to the question of whether $\dot{\alpha} \mu \alpha \rho \tau i \alpha$ is a flaw or an action at the end of the article.

9 These views often have been labelled the 'moral' view and contrasted with readings of $\dot{\alpha} \mu \alpha \rho \tau$ ti $\alpha$ as an intellectual 'error' (e.g. Bremer [n. 2], 91-7). But as more recent contributions have made clear (e.g. M. Heath, Ancient Philosophical Poetics [Cambridge, 2013], 91; Cessi [n. 8], 248-9), this is misleading: an intellectual error might just as well involve a moral failure and cannot be restricted to involuntary mistakes of fact only. To avoid repeating this erroneous dichotomy, I have labelled these readings 'blameworthy ignorance' views.
} 
A common argument in favour of these readings is based on Aristotle's rejections of

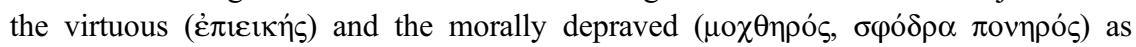
unsuitable for the tragic plot. ${ }^{10}$ The train of thought is as follows: if Aristotle prefers the tragic hero to be neither morally outstanding nor morally depraved, this does not merely mean that the moral character of the hero must be in-between these extremes, but that $\dot{\alpha} \mu \alpha \rho \tau i \alpha$ is the explanation of what makes him average. With this as a backdrop, it is claimed that the protagonist at least has to be partially responsible for the $\dot{\alpha} \mu \alpha \rho \tau i \alpha$.

While this argument leads some scholars to the conclusion that $\dot{\alpha} \mu \alpha \rho \tau i \alpha$ is a general moral weakness, ${ }^{11}$ others elaborate upon it by coupling it with Aristotle's theory of $\dot{\alpha} \kappa \rho \alpha \sigma i \alpha .{ }^{12}$ This gives us a better grasp of how the shift from fortune to misfortune happens: the protagonist errs when blinded by desire and acts in ignorance against his better judgement. Consequently, $\dot{\alpha} \mu \alpha \rho \tau i \alpha$ is taken to be either the akratic disposition itself or an akratic action.

Although the suggestion accords well with Aristotle's description of the protagonist as average (or at least not fully virtuous), there is some reason to doubt that $\dot{\alpha} \mu \alpha \rho \tau i \alpha$ is linked with $\dot{\alpha} \kappa \rho \alpha \sigma i \alpha$, at least in the straightforward sense. As demonstrated, Aristotle is

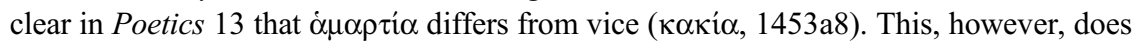
not sit well with a claim Aristotle makes about $\alpha \kappa \rho \alpha \sigma i \alpha$ in the ethics, namely that unqualified $\dot{\alpha} \kappa \rho \alpha \sigma i \alpha$ 'is censured not only as a $\dot{\alpha} \mu \alpha \rho \tau i \alpha$ but also as, in a way, vice

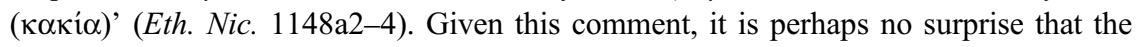
majority of modern opponents have dismissed the reading harshly. Although unqualified

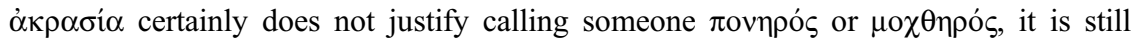
considered to be something worse than a 'mere' $\alpha \mu \alpha \rho \tau i \alpha$. This makes it hard to settle on the 'blameworthy ignorance' readings in their current form: they do not give a satisfactory answer to how a tragic $\alpha \mu \alpha \rho \tau i \alpha$ harmonizes with Aristotle's ethics. That being said, I do think that critics tend to dismiss these interpretations too quickly and unjustly overlook their merits - but for now it suffices to point out that the 'blameworthy ignorance' views meet with a challenge.

\section{b. Excusable ignorance views}

Another group of interpreters argue that $\dot{\alpha} \mu \alpha \rho \tau i \alpha$ is connected to an ignorance of particular circumstances for which one cannot be held responsible. ${ }^{13}$ Again, we find two versions of the view depending on whether $\dot{\alpha} \mu \alpha \rho \tau i \alpha$ is taken to be the ignorance residing within the agent or an act resulting from such ignorance. ${ }^{14}$ The defence for both readings is based on Eth. Nic. 3, where Aristotle claims that an unavoidable

${ }^{10}$ Cf. Schmitt (n. 8), 455-6; Østerud (n. 8), 75; Harsh (n. 2), 57-8.

${ }^{11}$ E.g. P. Manns, Die Lehre des Aristoteles von der tragischen Katharsis und Hamartia (Karlsruhe and Leipzig, 1883); Harsh (n. 2).

12 E.g. Schmitt (n. 8); Cessi (n. 8); Østerud (n. 8); Gresseth (n. 8).

13 Traditionally, these interpretations have been presented as taking $\dot{\alpha} \mu \alpha \rho \tau i \alpha$ as an intellectual 'error'. Since this label is misleading (cf. n. 9 above), I write 'excusable ignorance' to emphasize that these interpretations refer to a failure of knowledge for which one cannot be blamed.

${ }^{14}$ It is described as an ignorance that gives rise to mistaken acts by Kim (n. 3); Lucas (n. 4); L. Golden, 'Hamartia, ate, and Oedipus', CW 72 (1978), 3-12; Dawe (n. 3); M. Ostwald, 'Aristotle on hamartia and Sophocles' Oedipus Tyrannus', in M. von Schröder (ed.), Festschrift Ernst Kapp (Hamburg, 1958), 93-108; G.F. Else, Aristotle's Poetics: The Argument (Cambridge, MA, 1957); van Braam (n. 3); and I. Bywater, Aristotle: On the Art of Poetry (Oxford, 1909). In contrast, $\dot{\alpha} \mu \alpha \rho \tau i \alpha$ is characterized as an act by Hull (n. 3); H. House, Aristotle's Poetics (Westport, 1978), 82-99; Bremer (n. 2); and J.H. Reinkens, Aristoteles über Kunst, bes. über Tragödie (Vienna, 1870). 
ignorance of particular facts and subsequent regret make an action involuntary and pitiable.

A central argument in favour of these views springs from the statement that pity is evoked when someone suffers undeservedly ( $\left.\dot{\alpha} v \alpha \dot{\xi} \xi_{10}\right)$. Aristotle's definition of pity in the Poetics, they claim, ${ }^{15}$ rules out the possibility of understanding $\dot{\alpha} \mu \alpha \rho \tau i \alpha$ as being blameworthy; for if the hero's misfortune is to be acknowledged as undeserved, he cannot have any share in the responsibility for his own downfall. By turning to Aristotle's discussion of the involuntary (†ò ókov́otov) in Eth. Nic. 3, they further argue that a $\dot{\alpha} \mu \alpha \rho \tau i \alpha$ comes about without making the tragic hero responsible for his misfortune.

This leads up to a second argument: in his discussion of the involuntary in Eth. Nic. 3, Aristotle claims that an agent cannot be blamed for involuntary actions and that such situations evoke pity. One of the criteria of involuntariness is that the agent subsequently feels regret (Eth. Nic. 1110b22-3). Another is that the action happens 'because of

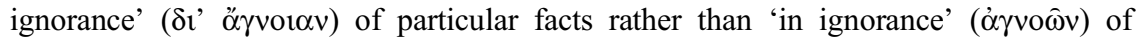
particular facts (Eth. Nic. 1110b24-1111a1). The difference is crucial: acting 'because of ignorance' means that the action happens owing to a pure lack of information, while acting 'in ignorance' means that the action happens because the agent voluntarily has put himself in a state of ignorance, such as anger or drunkenness. Given that the two

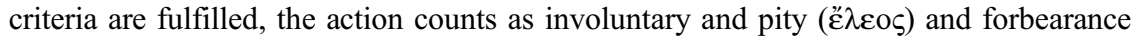

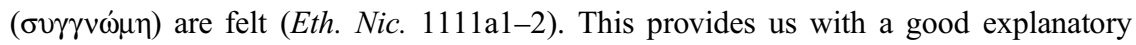
model of how $\alpha \mu \alpha \rho \tau i \alpha$ is excusable and the misfortune is undeserved: the hero makes an involuntary mistake because of ignorance of particular facts, and the misfortune that follows evokes our pity.

Although these readings explain how an involuntary mistake of fact may elicit pity successfully, they have two serious drawbacks. First, they do not offer us any explanation

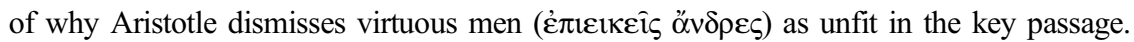
This is a problem, because the middle character is supposed to be different from the man of virtue and, furthermore, because there is nothing in Aristotle's account of involuntariness that suggests that our pity hinges on the moral character of the agent. As the issue concerns the next group of interpretations as well (that is, the 'open' readings), let us first have a closer look at these before laying out the critique fully. Second, these interpretations largely assume that moral responsibility is irreconcilable with suffering undeserved misfortune. They do not allow for any degrees of moral responsibility, and do not seriously consider the possibility that the protagonist may have partial share in the responsibility of his ruin. I shall elaborate upon and return to this critique in part 3.

\section{c. Open readings}

Rather than confining $\dot{\alpha} \mu \alpha \rho \tau i \alpha$ to one sense, a third group of critics argue that Aristotle leaves it up to the poet to decide what kind of failure it is that brings the tragic hero to misfortune. Some of them are indeed more flexible than others, as it varies how wide the possible range of failures is defined. But common to all is the claim that $\dot{\alpha} \mu \alpha \rho \tau i \alpha$ cannot be restricted to having just one meaning. Accordingly, I name them 'open' readings.

The view has gained wider acceptance among scholars in recent years, ${ }^{16}$ and has most prominently been defended by Stinton (n. 2). Against the 'excusable ignorance'

${ }^{15}$ Cf. Kim (n. 3), 49-50; Hull (n. 3), 288; Bremer (n. 2), 62.

${ }^{16}$ Cf. Heath (n. 9), 91-2; N. Sherman, 'Hamartia and virtue', in A.O. Rorty (ed.), Essays on Aristotle's Poetics (Princeton, 1992), 177-96, at 179-80; H. Wagner, Aesthetik der Tragödie von 
views, he argues that it would be too narrow to associate $\dot{\alpha} \mu \alpha \rho \tau i \alpha$ with a pitiable act caused by an involuntary ignorance of particular facts only: in the Poetics, he objects, it is not the act that counts as pitiable-but the fall from good to bad fortune (Stinton [n. 2], 229). The agent does not have to be entirely blameless to arouse pity, but the suffering must 'in some sense' be undeserved and cause disproportionate misery to the agent (Stinton [n. 2], 229-30). This allows us to extend the range of failures involved in $\alpha \mu \alpha \rho \tau i \alpha$ : it may be acts caused by ignorance, acts done through $\alpha \kappa \rho \alpha \sigma i \alpha$, and wrong

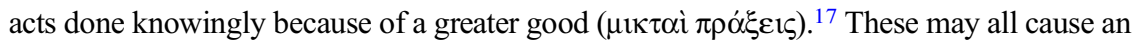
undeserved shift to misfortune, and we can thus reconcile Aristotle's description of the best tragic plot with several plays.

To allow for this flexibility, however, Stinton's reading needs to rest on an important

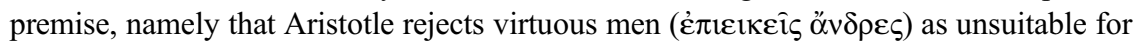
the best tragic plot only because the disaster of the very good man would inhibit tragic pleasure. The problem with this plot is that we would feel it to be unjust and thus morally repulsive, according to Stinton (n. 2), 226. In other words, the reading does not rule out the possibility that a flawless man could make an involuntary $\dot{\alpha} \mu \alpha \rho \tau$ í $\alpha$. Just like the 'excusable ignorance' views, the interpretation makes it hard to understand why Aristotle sees a need in dismissing the غ̇лıєıńs person in the first place.

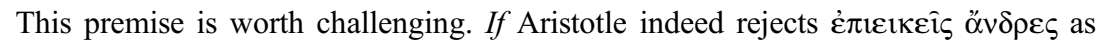
unsuitable because their undeserved misfortune would be overwhelming and arouse indignation, that would imply that the misfortune of flawless men is perceived as more undeserved than the misfortune of other people-even if they all come to ruin through the very same failure. In fact, we could imagine two characters suffering owing to an unavoidable mistake of fact. While one of them is unqualified good, the other is only average. Apart from that, nothing differs: they make the same involuntary mistake, and both of them suffer misfortune as a result. The implication of both Stinton's and the 'excusable ignorance' view's readings is that the suffering of the perfect agent would be morally outrageous, while the suffering of the average agent would elicit pity in a manner appropriate to tragedy. But that is less likely to be Aristotle's view: he nowhere in his ethics claims that our pity hinges on the moral character of the agent. Given that the misfortune is undeserved, there is no reason to think that we should respond differently to misfortune caused by an innocent mistake when it is made by either a virtuous or an average agent.

Stinton's explanation of why the first plot is inappropriate is, then, not without problems. ${ }^{18}$ This also applies to the 'excusable ignorance' views. A more plausible explanation of why Aristotle dismisses virtuous people as unsuitable for the best tragedy, I will argue, is that it is impossible for them to come to ruin through a

Aristoteles bis Schiller (Würzburg, 1987), 27-8; S. Halliwell, Aristotle's Poetics (London, 1986), 220; M.C. Nussbaum, The Fragility of Goodness (Cambridge, 1986), 382-3; Sorabji (n. 7), 295-8. Earlier proponents include I.M. Glanville, 'Tragic error', CQ 43 (1949), 47-56; and Butcher (n. 5).

${ }_{17}$ Stinton speaks of $\alpha \mu \alpha \rho \tau i \alpha$ as an act. Still, my objections would be valid even if we include the interpretation that $\dot{\alpha} \mu \alpha \rho \tau i \alpha$ is some ignorance residing within the agent.

${ }^{18}$ M. Nussbaum, 'Tragedy and self-sufficiency', in A.O. Rorty (ed.), Essays on Aristotle's Poetics (Princeton, 1992), 261-90, at 279 mentions another possible explanation of why Aristotle dismisses the first plot as unable to arouse pity and fear, namely because he objects to the unexplained decline of the good person - and not the decline of the good person as such. But that is also less likely: Aristotle explicitly states that the protagonist is a 'person in-between these cases' (ó $\mu \varepsilon \tau \alpha \xi \dot{v}, 1453 \mathrm{a}$; ; cf. Lucas [n. 4], 141), which rules out this possibility. 
$\dot{\alpha} \mu \alpha \rho \tau i \alpha$. It remains to discuss whether this is an acceptable interpretation, and I make a case for that in part 3. But for now it is clear that a central premise of their readings runs into a considerable problem.

\section{HAMARTIA RECONSIDERED}

So far I have criticized prevailing readings of $\alpha \mu \alpha \rho \tau i \alpha$. Now I turn to the task of proposing an account that solves their problems and suggest that the notion is better explained as weakness of will ( $\dot{\alpha} \kappa \rho \alpha \sigma i \alpha)$ in a qualified sense, which is triggered either by temper $(\theta \nu \mu o ́ s)$ or by a desire for fine, good and choiceworthy things. First, I argue on grounds of the Poetics that an understanding of $\dot{\alpha} \mu \alpha \rho \tau i \alpha$ as a moral weakness is more in accordance with the central claims Aristotle makes about the tragic plot. Then, I bring in the Nicomachean Ethics: rather than suggesting that all forms of $\alpha \kappa \rho \alpha \sigma i \alpha$ are appropriate for explaining how a tragic $\dot{\alpha} \mu \alpha \rho \tau i \alpha$ relates to ignorance, as previous proponents have, I exclusively link it with qualified $\dot{\alpha} \kappa \rho \alpha \sigma i \alpha$, which Aristotle considers to be

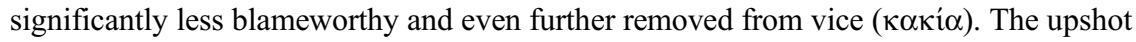
is that the tragic hero gets blinded and overlooks important particular facts when angry or when pursuing fine and desirable things—-such as victory, honour and wealth.

\section{a. Evidence in the Poetics}

What evidence is there in the Poetics that the tragic hero comes to ruin through a moral weakness? Let us start by looking at two central claims made by Aristotle: (i) that the protagonist should be a 'middle' character; and (ii) that the plot should be structured in accordance with necessity and probability.

i. The need for a middle character

In his instructions for the tragic plot, Aristotle claims that neither perfectly virtuous nor absolutely vicious ${ }^{19}$ people are suitable for tragedy. His argument is that neither of these characters will contribute to a truly tragic plot, which produces both pity ( $\varepsilon^{\prime} \lambda \varepsilon \sigma \varsigma$ ) and

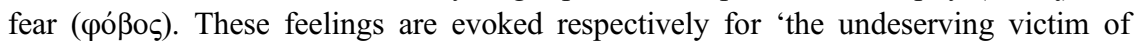
adversity' and 'for the one like ourselves' (1453a4-6). The fall or rise of utterly vicious people are not able to evoke these feelings. But why are morally outstanding people unsuitable? The answer to that question, I claim, gives us a better grasp on $\dot{\alpha} \mu \alpha \rho \tau i \alpha$.

If such persons are shown to be changing from prosperity to adversity, this provokes neither pity nor fear, according to Aristotle-it is simply 'repulsive' (1452b30-6). ${ }^{20}$ As

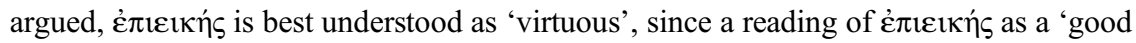
but fallible person' would leave such people without any distinctive features which make them different from the later prescribed middle character. Aristotle does not explicitly tell us why the pre-eminent character's shift from good to bad fortune is

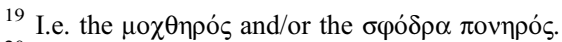

20 Although Aristotle claims that a scenario where the $\dot{\varepsilon} \pi \varepsilon \imath \kappa \eta \dot{s}$ is moving from prosperity to adversity 'is not fearful nor yet pitiable', it still seems as they could evoke pity given his later definition of

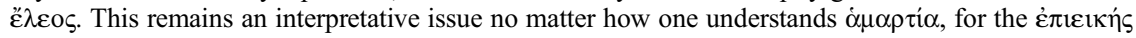
would in any case not deserve ruin. 
unsuitable. Yet the broader context of the $\dot{\alpha} \mu \alpha \rho \tau i \alpha$ passage still leaves us with important clues to explain this preference.

In light of Aristotle's demand that the poet should rather portray the 'middle' character ( $\dot{o} \mu \varepsilon \tau \alpha \xi u$ ), it seems fair to suppose that Aristotle's preference is grounded in the moral quality of the hero. My argument is as follows: the reason why Aristotle rejects the morally outstanding must be that such a person would not make any morally wrong decisions. He would make no mistakes that reflect negatively on his moral character, since there is by definition nothing morally criticizable by him. He has no $\dot{\alpha} \mu \alpha \rho \tau i \alpha$ and is therefore of no interest for the tragic plot. The middle character, in contrast, would have or commit a $\dot{\alpha} \mu \alpha \rho \tau i \alpha$ precisely by virtue of being imperfect. Naturally, he should not be vicious, as that would make him worse than a middle character. But he will by definition have at least one flaw.

Against this reading, Kim infers, on the basis of Aristotle's claim that the hero's

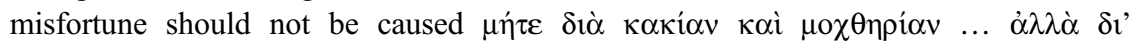
$\dot{\alpha} \mu \alpha \rho \tau i \alpha v \tau \imath v \dot{\alpha},{ }^{21}$ that 'the primal cause of $\delta v \sigma \tau v \chi i \alpha$ can be said to have nothing to do with the moral or culpable aspect' (1453a8-10; Kim [n. 3], 40). However, moral qualities between the two extremes-moral wickedness and pure virtuousness - are at the same time eliminated. This brings me back to the critique of the assumption that the hero cannot have any share in the responsibility for his misfortune, which is widespread among scholars defending 'excusable ignorance' views. ${ }^{22}$ Among them is Bremer (n. 2), 62, whose rejection of the tragic hero's 'guilt' becomes relevant:

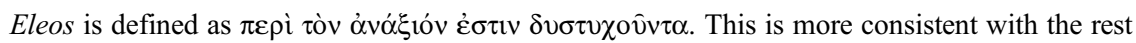
of the Poetics ... than the passing remark that the غ̇лıєıкń is declared unfit for the tragic stage ... Consequently, the hero's downfall should not be the result of his wicked way of life; it

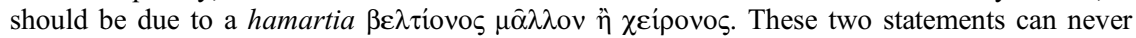
be reconciled with an interpretation of hamartia in which guilt is stressed.

Here, Bremer and the other scholars who promote this view miss an essential point: to be morally responsible for one's $\dot{\alpha} \mu \alpha \rho \tau i \alpha$ does not mean that one deserves a tragic outcome.

To make my point that one might be only partially responsible for a disastrous outcome clearer, consider the following counterexample. ${ }^{23}$ Gavrilo Princip assassinated Franz Ferdinand and Sophie Chotek on 28 June 1914. They were both killed in the shooting, and for this Princip is fully to blame. The assassination set forth a chain of events that resulted in World War I. Princip could, therefore, be held responsible for one important cause of the war, but it still seems utterly unfair to make him responsible for World War I as a whole. My point is: one can (as a cause) be held responsible for a starting point, without being held fully responsible for the whole chain of unforeseen and independent events resulting from it. A starting point is only that, a starting point: further factors will eventually enter the picture. It is these further factors that decide to which degree one can be held responsible for the final results. If one voluntary action sets off a chain of events that ends in disaster, it does not automatically follow

21 'not through vice and depravity but through some $\dot{\alpha} \mu \alpha \rho \tau i \alpha$ '.

${ }^{22}$ E.g. Kim (n. 3), 49-50; Cyzyk (n. 3), 20; Hardison (n. 3), 183-4; Potts (n. 3), 81; van Braam (n. 3), 271-2.

${ }^{23}$ This example only demonstrates that it may be unreasonable to hold someone fully responsible for a terrible outcome. It does not claim that the fault that triggered the outcome in this particular case qualifies as a $\dot{\alpha} \mu \alpha \rho \tau i \alpha$ as per Poetics 13. 
that one can be held responsible for all of the great damage caused. But one will be responsible for the first move, unless the first action was involuntary to begin with. Following this example, we might distinguish between responsibility with regard to the starting point and to the effects. Given that distinction, it could be said about the tragic hero that he could be fully responsible for his $\dot{\alpha} \mu \alpha \rho \tau i \alpha$ but only partially responsible for the tragic ruin which follows. It is, then, entirely possible to hold the protagonist responsible for his $\alpha \mu \alpha \rho \tau i \alpha$ without at the same time insisting that he deserves the far more serious outcome.

If we were to say that an agent deserves misfortune under the mere condition that he has made a mistake of moral importance-like Kim, Bremer and numerous other scholars do-we would not operate with nuances between 'vicious' and 'morally outstanding'. Such an interpretation does not give any room for states between the two extremes, and it all appears as a choice between black and white, or between good and evil. But that is certainly not how Aristotle or we think about ethical issues, so they run into a problem here. After all, Aristotle admits that it is hard to become fully virtuous and that there are many ways of going astray (Eth. Nic. 1106b28-9). But if we fall short when it comes to virtue as a whole, this does not render us villains. If the states in-between perfect virtue and pure vice are taken into consideration, it is now possible to reconcile Aristotle's two claims. The statement that the غ̇лıєкń is unfit for tragedy is not just a 'passing remark'. Rather, it underscores a crucial feature of the middle character, namely that he is not perfect. ${ }^{24}$

Given the interpretation of $\alpha \mu \alpha \rho \tau i \alpha$ as a 'character flaw', it is clear that Aristotle

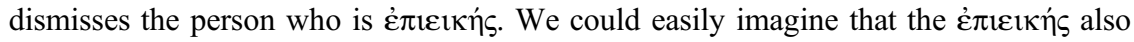
suffered owing to an unavoidable ignorance of particular facts, since such an error happens independently of one's moral dispositions. In that case, there does not seem to be any reason for Aristotle to exclude the fully virtuous person from tragedy, since he would equally meet the requirements for evoking pity and fear: he would certainly suffer undeservedly. And if the cause of his bad fortune were due to something external, something outside him—such as a lack of important information-we would have reason to feel fear, since this could also happen to anyone. But this option is precisely rejected by Aristotle himself. ${ }^{25}$

Some scholars are reluctant to understand $\dot{\alpha} \mu \alpha \rho \tau i \alpha$ as a flaw because Aristotle explicitly states that the change of fortune happens 'because of a great $\alpha \mu \alpha \rho \tau \tau^{\prime} \alpha$ ' $\left(\delta \mathrm{t}^{\prime}\right.$ $\dot{\alpha} \mu \alpha \rho \tau i \alpha v \mu \varepsilon \gamma \alpha \dot{\alpha} \lambda \nu)$. The adjective $\mu \varepsilon \gamma \alpha \dot{\alpha} \lambda \eta$, they maintain, ${ }^{26}$ excludes such a reading: if it indeed was the case that $\dot{\alpha} \mu \alpha \rho \tau i \alpha$ refers to a moral flaw, a 'big' flaw would lower the moral quality of the hero to less than average and go against what Aristotle otherwise writes in the passage. In response to this counterargument, I would point out that it relies on a reading of $\mu \varepsilon \gamma \alpha \dot{\alpha} \lambda \eta$ as 'great' (as in the physical sense of 'big'). The adjective, however, can also mean 'momentous', 'significant' or 'important',

24 The same point applies to K. von Fritz, Antike und Moderne Tragödie: Neun Abhandlungen (Berlin, 1962), 1, who leaves no room for nuances in writing that the debate about $\alpha \mu \alpha \rho \tau i \alpha$ concerns 'zwei Parteien gegenüber, von denen die eine behauptet, dass z.B. Ödipus und Antigone unschuldig leiden, während die andere Partei nicht nur ihre Schuld nachzuweisen sucht, sondern auch, dass sie "gerechterweise" leiden'.

${ }^{25}$ The wording 'because of some $\alpha \mu \alpha \rho \tau i \alpha$ ' ( $\delta$ '’ $\alpha \mu \alpha \rho \tau i \alpha v \tau \imath v \alpha$, 1453a9-10) might be taken to suggest a range of possible failures, at least initially. But Aristotle's emphasis on the need for a middle character throughout Poetics 13 makes such a reading less likely: if any failure could trigger the shift of fortune in the most beautiful tragedies, it is hard to see why a middle character should be needed.

${ }^{26} \operatorname{Kim}$ (n. 3), 40-1; House (n. 14), 93-4; Bremer (n. 2), 23; Dawe (n. 3), 120-1; Lucas (n. 4), 145. 
which allows us to resolve this apparent problem. ${ }^{27}$ On this reading, the character flaw is 'momentous' because it triggers a disastrous outcome and brings the protagonist to ruin - and not because the character flaw itself is a serious moral defect. Given that $\dot{\alpha} \mu \alpha \rho \tau i \alpha$ is what causes the shift from good to bad fortune, it is entirely reasonable to take $\mu \varepsilon \gamma \alpha \dot{\alpha} \lambda \eta$ to have this latter sense.

\section{ii. Necessity and probability}

Another important feature for understanding $\alpha \mu \alpha \rho \tau i \alpha$ is the role of necessity and probability. According to Aristotle, the connections which make up a tragic plot should be necessary or at least probable: the chain of events should be so structured that, if one event is displaced or removed, the sense of the whole will be disturbed and dislocated (1451a30-4). This requirement, I propose, implies that the imperfection(s) of the protagonist must be relevant to the development of the plot.

This implication of Aristotle's statement is easier to understand if we take into consideration the already emphasized claim. So far it has been established (i) that Aristotle requires the protagonist to be a middle character who by definition has some imperfection. In addition, Aristotle is clear in the Poetics (ii) that the characters should be included in a tragic plot for the sake of their actions and not merely because they are of a certain type (1449b36-1450a 7, 1450a15-23, 1450a38-9, 1450b3-4). With these claims as a backdrop, Aristotle's additional requirement about necessity and probability sheds new light on the relevance of the imperfection of the tragic hero: the incidents in the plot should be so structured that the displacement or removal of one of them would disturb or dislocate the whole (1451a30-4). If the presence or absence of something makes no discernible difference, by contrast, it is no part of the whole (1451a35). These remarks imply that only the events that are relevant to the development of the plot should be included in a play. Events that make no difference to the play as a whole are-properly speaking - not parts of it. Since Aristotle also requests the protagonist to be a middle character and his moral character to be expressed through his actions, it is now only fair to expect that his actions are relevant for the development of the plot. These actions should not be episodic events that are irrelevant for understanding the story as a whole. Rather, they should be inevitable for understanding the development of the plot and thus qualify as true parts of the whole.

An example from Greek tragedies may illustrate my argument. In Oedipus Tyrannus $(=O T)$, which Aristotle repeatedly uses to illustrate his points, ${ }^{28}$ Sophocles portrays Oedipus as impetuous rather than a paragon of virtue. ${ }^{29}$ To begin with, Oedipus firmly declares that he will track down and punish Laius' murderer (OT 216-45). But when Tiresias confronts him with the truth, Oedipus refuses to believe him and reacts with rage: he contends that Tiresias is corrupted and blames him for secretly working for Creon, whom he accuses of desiring his position as the king of Thebes (OT 380403). When Creon later tells him the truth again, Oedipus furiously demands that he should be executed (OT 623). These scenes reveal that Oedipus has a temper that occasionally comes out of hand. Given my argument, these scenes are genuine parts

\footnotetext{
27 Aristotle uses $\mu \varepsilon \gamma \alpha \dot{\alpha} \lambda \alpha$ to describe some things as 'important' (rather than 'big') in 1456b4, thus demonstrating that he was familiar with this sense of the adjective.

${ }_{28} 1452 \mathrm{a} 24-6 ; 1453 \mathrm{~b} 6-7,31 ; 1454 \mathrm{~b} 7-8 ; 1455 \mathrm{a} 18$. For more about Aristotle's engagement with the OT, cf. P.J. Finglass, Sophocles: Oedipus the King (Cambridge, 2018), 82-3.

29 True enough, Oedipus is not characterized only by angry impetuousness. For reflections on his compassion, cf. Finglass (n. 28), 41-51.
} 
of the plot: they illustrate Oedipus' middle character, which is essential for understanding how his $\dot{\alpha} \mu \alpha \rho \tau i \alpha$ could come about and why he fails to recognize the truth to begin with. ${ }^{30}$ Given the 'excusable ignorance' views, on the contrary, these incidents have no share in the development of the plot because they are irrelevant for understanding his downfall. If we accept these readings, Sophocles could in fact remove these parts of the play without affecting the development of the plot. The character of Oedipus - or of other tragic protagonists, for that matter-could in that case be of another kind, and the sense of the whole would still not be disturbed. That, however, goes against Aristotle's own requirement about necessity and probability and is not a satisfactory explanation of Oedipus' hasty temper, at least not from an Aristotelian point of view.

This point gives rise to a third critique of the 'excusable ignorance' views. In general, the problem is this: if the protagonist involuntarily lacks knowledge of important circumstances, then what kind of character the protagonist has would be merely incidental and not instrumental to the pattern of events. ${ }^{31}$ But, as argued, it would not make sense for Aristotle to insist that the protagonist should be a middle character unless this particular circumstance makes the development of the plot necessary or probable. To portray the protagonist as imperfect, without this being relevant to the series of events that make up a tragedy, does not contribute to the plot and weakens rather than strengthens the unity of the events. ${ }^{32}$ Given Aristotle's claims, the poet should omit unnecessary trivia and focus on what makes the shift from good to bad fortune likely.

To sum up, there are indications in the Poetics that strongly point toward an understanding of $\dot{\alpha} \mu \alpha \rho \tau i \alpha$ as a moral failure conditioned upon the character of the hero. But if this is correct, then we need to know: how can Aristotle allow for the protagonist to be blamed for his ignorance, but without being blamed for having some sort of vice? It is time to turn to Aristotle's ethics.

\section{b. Evidence in the Nicomachean Ethics}

To get a better grasp of how ignorance relates to $\dot{\alpha} \mu \alpha \rho \tau i \alpha$, Aristotle's ethics proves vital. As demonstrated, proponents of the 'excusable ignorance' views appeal to Aristotle's theory of involuntary action in Eth. Nic. 3 to explain the tragic $\dot{\alpha} \mu \alpha \rho \tau i \alpha$ : the protagonist acts faulty 'because of ignorance' ( $\delta \mathrm{r}$ ' ö $\gamma$ vor $\alpha v)$ of particular facts. The account I develop in what follows, in contrast, stresses that the tragic $\alpha \mu \alpha \rho \tau i \alpha$ makes the hero act 'in ignorance' ( $\dot{\alpha} \gamma v \hat{\omega} \hat{\omega})$ of particular facts because he is led astray either by temper or by a desire for fine and choiceworthy things. ${ }^{33}$ Thereby he ends up overlooking a few, but still essential, facts. He is akratic in a qualified sense; but in contrast to plain $\dot{\alpha} \kappa \rho \alpha \sigma i \alpha$, qualified $\dot{\alpha} \kappa \rho \alpha \sigma i \alpha$ does not justify us attributing any degree of vice

${ }^{30} \mathrm{I}$ return to a full interpretation of $O T$ in subsection $c$.

31 E.g. Bremer (n. 2), 158 insists that Oedipus' alleged faults are incidental rather than instrumental to the pattern of events.

${ }^{32}$ Harsh (n. 2), 58 makes a similar point: 'One may recall how Henry VIII ate a roast of chicken, but none of us can imagine how Oedipus would do so. Eating is not a part of the artistic creation of Oedipus. He exists only in certain aspects directly relevant to his prosperity and his adversity.'

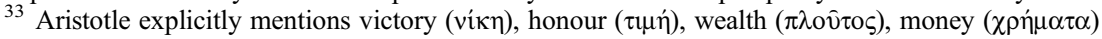

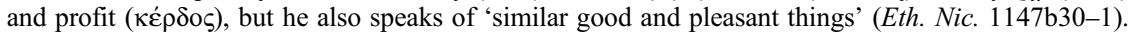
Rather than repeatedly listing up all these examples, I variably refer to them as 'fine', 'excellent', 'good' or 'desirable things', which are the descriptions Aristotle uses. Furthermore, these objects trigger various subtypes of qualified $\alpha \kappa \rho \alpha \sigma i \alpha$ : we add a condition and say that a person is akratic 'with regard to honour', 'with regard to money', etc. (Eth. Nic. 1147b33-4). Since Aristotle treats them as a generic type when speaking of their features and blameworthiness, I do so too. 
to the hero. ${ }^{34}$ In what follows, I bring in Aristotle's account of weakness of will in Eth. Nic. 7 to explain how the hero fails to grasp the right, particular facts.

i. Blinded by temper or by fine and desirable things

The main idea with weakness of will is that one somehow acts against one's better judgement. This implies (a) that the agent is capable of realizing what would be the best choice and therefore not completely vicious, and (b) that the agent is not completely virtuous, since he falls short in practice. In other words, this phenomenon occurs among people who are neither wicked nor morally flawless. The target group of $\alpha \kappa \rho \alpha \sigma i \alpha$ thus appears to be somehow similar to the characteristics of the tragic hero in Poetics 13. One might therefore reasonably wonder: is there any connection between $\dot{\alpha} \mu \alpha \rho \tau i \alpha$ and $\dot{\alpha} \kappa \rho \alpha \sigma i \alpha$ and, if so, what is this connection more explicitly? My suggestion is this: tragic $\dot{\alpha} \mu \alpha \rho \tau i \alpha$ is linked to weakness of will, but only to the qualified type-which

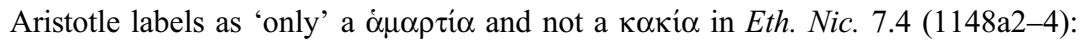

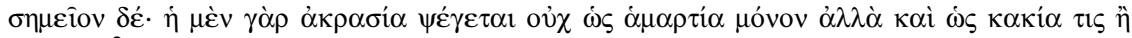

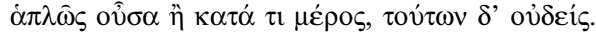

An indication of what we are saying is that $\dot{\alpha} \kappa \rho \alpha \sigma i \alpha$ is censured not only as a $\dot{\alpha} \mu \alpha \rho \tau$ tí but also as, in a way, vice, either without qualification or in terms of some particular sort of badness, whereas none of the types just mentioned [that is, the qualified types of $\dot{\alpha} \kappa \rho \alpha \sigma i \alpha]$ is censured in this way.

The qualified types of $\alpha \kappa \rho \alpha \sigma i \alpha$, which are triggered by temper or by a desire for fine and desirable objects, are significantly less blameworthy than proper $\dot{\alpha} \kappa \rho \alpha \sigma i \alpha$. In the following paragraphs, I show how Aristotle arrives at this conclusion and how it applies to our understanding of $\dot{\alpha} \mu \alpha \rho \tau i \alpha$.

To draw a line from $\dot{\alpha} \mu \alpha \rho \tau i \alpha$ to $\alpha \kappa \rho \alpha \sigma i \alpha$ involves emphasizing Aristotle's requirements to the moral quality of the protagonist. As demonstrated, Aristotle rules out the sorts of persons who are unsuitable for the tragic plot: the virtuous (غ̇лıєкńs)

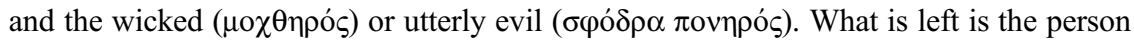
in-between: the middle character ( $\dot{o} \mu \varepsilon \tau \alpha \xi \dot{v})$. It is only he who can be involved in a truly tragic plot. In Eth. Nic. 7.10, Aristotle gives a description of the akratic person that is strikingly similar to that of the tragic hero (1152a15-18):

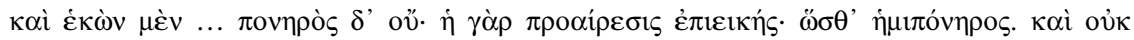

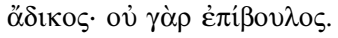

And he [the akratic person] acts voluntarily ... but is not a bad person, since what he decides on is decent; so he is half-bad. He is not unjust either, since he is not a plotter.

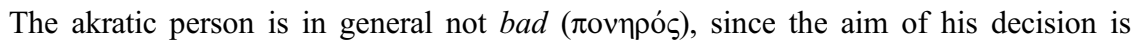

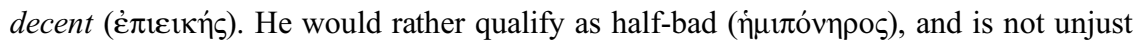

34 Aristotle contrasts this phenomenon with 'unqualified' ( $\dot{\alpha} \pi \lambda \hat{\omega} \varsigma)$ weakness of will (1147b31-5, 1148a4-11) and varies his descriptions of it: he writes that we call someone akratic by virtue of

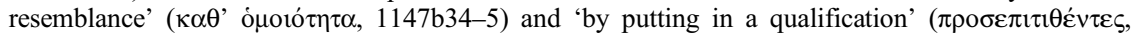
1148b6-7). The point is that we always add a qualification: we say that someone is akratic 'with regard to money', 'with regard to temper' or 'with regard to honour' (1147b33-4, 1148b13-14). Following H. Lorenz, 'Nicomachean Ethics VII.4: plain and qualified akrasia', in C. Natali (ed.), Aristotle's Nicomachean Ethics, Book VII. Symposium Aristotelicum (Oxford, 2009), 72-101, I refer to this phenomenon as 'qualified' $\alpha \kappa \rho \alpha \sigma i \alpha$. 


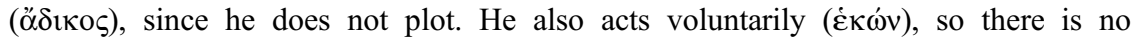
doubt that his weakness is connected to his moral character and does not constitute an exception that may be excused. Hence, it appears fair to acknowledge that the moral quality of the tragic hero and the akratic person is about the same-independent of whether one maintains that this moral quality plays a causal role in the downfall of the hero.

But this conclusion, as argued in part 2, calls for a refinement; for Aristotle attributes different degrees of blameworthiness to different forms of $\alpha \kappa \rho \alpha \sigma i \alpha$. The previous 'blameworthy ignorance' views meet with a challenge: Aristotle states that plain and

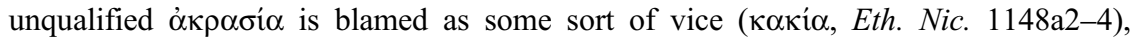

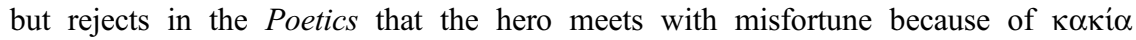
(1453a9). How are we to solve this?

In contrast to earlier interpreters who define $\alpha \mu \alpha \rho \tau i \alpha$ as a failure related to general $\dot{\alpha} \kappa \rho \alpha \sigma i \alpha$, I suggest that $\dot{\alpha} \mu \alpha \rho \tau i \alpha$ is better explained as $\dot{\alpha} \kappa \rho \alpha \sigma i \alpha$ in a qualified sense, which Aristotle describes as only a $\dot{\alpha} \mu \alpha \rho \tau i \alpha$ and not a $\kappa \alpha \kappa i \alpha$. More specifically, this sort of $\alpha \kappa \rho \alpha \sigma i \alpha$ is linked to temper $(\theta \nu \mu o ́ \varsigma)$ and to the desire for victory, honour, profit and wealth. Such things are not necessary, but desirable in their own right, and they can be taken to excess (Eth. Nic. 1147b29-35). Being weak-willed with regard to these things is only $\dot{\alpha} \kappa \rho \alpha \sigma i \alpha$ in a qualified sense, since such people are called weak-willed only by virtue of resemblance and we add a qualification such as 'with regard to honour' or 'with regard to temper' when speaking of them (Eth. Nic. 1147b33-5). This has consequences for their blameworthiness (Eth. Nic. 1148a2-4): while we tend to blame unqualified $\dot{\alpha} \kappa \rho \alpha \sigma i \alpha$ not only as a $\dot{\alpha} \mu \alpha \rho \tau i \alpha$ but also as some sort of $\kappa \alpha \kappa i \alpha$, this is not the case when speaking of $\dot{\alpha} \rho \rho \alpha \sigma^{\alpha} \alpha$ in a metaphorical sense. In the latter case we do not hold $\dot{\alpha} \kappa \rho \alpha \sigma i \alpha$ to be some badness-it is only a $\dot{\alpha} \mu \alpha \rho \tau i \alpha$. Thus qualified $\dot{\alpha} \kappa \rho \alpha \sigma i \alpha$ significantly differs when it comes to blame: it is not comparable to vice.

Why is qualified $\dot{\alpha} \kappa \rho \alpha \sigma i \alpha$ less blameworthy than proper $\dot{\alpha} \kappa \rho \alpha \sigma i \alpha$ ? The reasons are different for the various types of qualified $\dot{\alpha} \kappa \rho \alpha \sigma i \alpha$, and they also vary slightly when it comes to their blameworthiness. Let us begin with the desire for fine and choiceworthy things and then look into temper. As remarked, Aristotle describes the objects of qualified $\dot{\alpha} \kappa \rho \alpha \sigma i \alpha$ as desirable in themselves and not necessary, and he points to victory, honour and wealth as examples. This is in contrast to bodily goods, which are necessary and belong to the sphere of self-indulgence and moderation (Eth. Nic. 1147b23-8). He makes a similar claim in Eth. Nic. 1148a22-6, ${ }^{35}$ where objects such as wealth, profit, victory and honour are said to be generically fine and good, since they are by nature desirable. ${ }^{36}$ To pursue the pleasures arising through these latter things are less serious than pursuing the bodily pleasures arising through touch and taste, seemingly because the latter pleasures are pursued by the intemperate person as well. While the intemperate person decides on the pursuit of these bodily pleasures, the

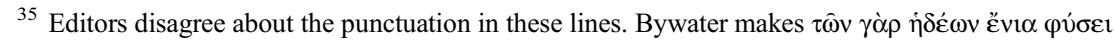

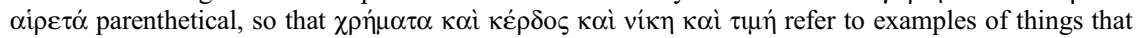
are in-between being 'naturally desirable' and 'naturally the contrary'. J.A. Stewart, Notes on the

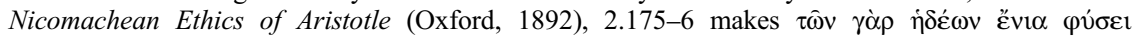

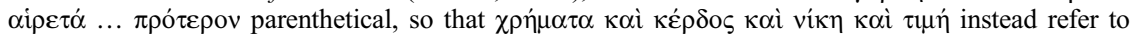
examples of 'generically fine and good' things. I follow Stewart, as Aristotle describes such items as 'naturally fine and good' in 1148a29-30 and as 'naturally desirable' in 1148b3.

${ }^{36}$ One might think it strange that profit and wealth qualify as desirable by nature. S. Broadie, 'Philosophical introduction', in Aristotle: Nicomachean Ethics (Oxford, 2002), 9-91, at 56 offers an explanation: 'this cannot mean that they are desirable as ends in themselves; it must mean that their desirability is not a matter of biological necessity, but engages our distinctively human nature.' 
unqualified weak-willed person gives in to the same pleasures against his own decision and thought (Eth. Nic. 1148a13-17). The person who is weak-willed only in a qualified sense, however, gives in to other sorts of pleasures, namely those arising from things that are fine, good and desirable in their own right.

This explanation, however, only covers the objects of pleasure that are characterized as unnecessary, fine and excellent. It does not cover temper $(\theta v \mu$ ó $\varsigma)$, which is perhaps better described as a different sort of desire (ö $\rho \varepsilon \xi 1 \varsigma) .{ }^{37}$ In Eth. Nic. 7.6, Aristotle turns to a more specific explanation of why $\alpha \kappa \rho \alpha \sigma i \alpha$ triggered by temper is less serious than $\dot{\alpha} \kappa \rho \alpha \sigma i \alpha$ relating to appetite $(\dot{\varepsilon} \pi \imath v \nu \mu i \alpha)$. The chapter provides us with some further reasons for grasping how qualified $\dot{\alpha} \kappa \rho \alpha \sigma i \alpha$ is different when it comes to blameworthiness, but it also poses us with certain challenges when interpreting this sort of $\dot{\alpha} \kappa \rho \alpha \sigma i \alpha .{ }^{38}$ In the case of $\dot{\alpha} \kappa \rho \alpha \sigma i \alpha$ with regard to temper, Aristotle explains the difference by answering that temper is related to reason, whereas appetite is not.

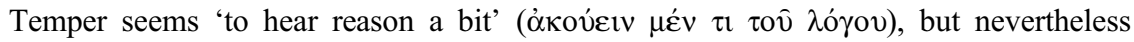
'mishears' ( $\pi \alpha \rho \alpha \kappa o v ́ \varepsilon v v)$ it (Eth. Nic. 1149a25-6). Aristotle's examples are overhasty servants who run out before they have heard all the instructions and then fail ( $\dot{\alpha} \mu \alpha \rho \tau \dot{\alpha} v o v \sigma \mathrm{l})$ to carry out the order and dogs that bark at a sound before discovering whether there is a friend who is there (Eth. Nic. 1149a27-9). To be weak-willed with regard to temper is 'in a way' like being overcome by reason, according to Aristotle, while being weak-willed with regard to appetite is not (Eth. Nic. 1149b2-3).

For our purposes, it is especially interesting that $\alpha \kappa \rho \alpha \sigma i \alpha$ triggered by temper arises in situations where the agent reacts to 'unprovoked aggression' (ט̈ßpiৎ) or 'insult' ( $\lambda^{\lambda}(\gamma \omega \rho i \alpha)$. In other words, it is not the same as wanton aggression but is better understood as a hasty reaction to such behaviour. Given that reason or appearance informs the agent about aggression or insult, temper moves into angry mode at once 'as if having reasoned it out that this sort of thing is cause for going to war' (Eth. Nic. 1149a33-4). A further indication that $\dot{\alpha} \kappa \rho \alpha \sigma i \alpha$ connected to temper is different from wanton

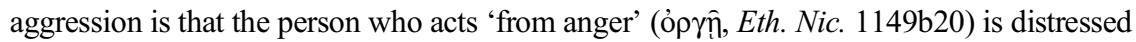
when he does it, whereas the unprovoked aggressor feels pleasure (Eth. Nic. 1149b20-1). If the things that justify anger the most are the more unjust, Aristotle adds, so too is weakness of will triggered by appetite, since temper involves no wanton aggression (Eth. Nic. 1149b21-3).

${ }^{37}$ Indeed, temper may also play a positive role in the acquisition of virtue. Cf. Pol. 1327b36-8.

38 One such challenge is whether qualified $\dot{\alpha} \kappa \rho \alpha \sigma i \alpha$ is identical with 'thumetic' $\dot{\alpha} \kappa \rho \alpha \sigma^{\prime} \alpha$, or whether the latter is one among several cases of qualified $\dot{\alpha} \kappa \rho \alpha \sigma i \alpha$. In Eth. Nic. 7.4, Aristotle mentions temper ( $\theta v \mu o ́ \varsigma, 1147 \mathrm{~b} 34)$ in a list of examples of qualified $\alpha \kappa \rho \alpha \sigma i \alpha$, alongside wealth, profit and honour. Furthermore, when referring to money, profit, victory and honour as 'fine and good' later in Eth. Nic. 7.4, Aristotle opens that sentence by stating that 'some appetites and pleasures' ( $\tau \hat{\omega} \mathrm{V}$

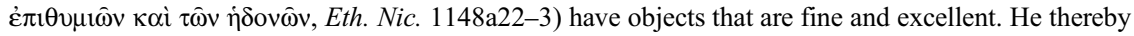
makes it clear that at least some of his examples are objects of appetite. Moreover, Aristotle pays special attention to anger in his account of thumetic $\dot{\alpha} \kappa \rho \alpha \sigma i \alpha$ in Eth. Nic. 7.6; but he does not bring in any of the other examples of qualified $\dot{\alpha} \rho \rho \sigma$ í $\alpha$ from Eth. Nic. 7.4. Instead, he writes that there is more sympathy for people who follow natural desires and that temper or irascibility is more natural than 'appetites for unnecessary things' $(\tau \hat{\omega} v \dot{\varepsilon} \pi \imath \theta v \mu \imath \hat{\omega} v \ldots \tau \hat{\omega} v \mu \grave{\eta} \dot{\alpha} v \alpha \gamma \kappa \alpha i \omega v$, Eth. Nic. 1149b7-8), which was how he earlier classified victory, honour, profit and wealth in Eth. Nic.

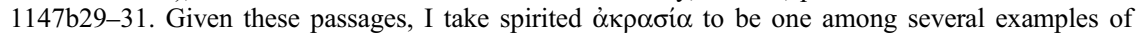
qualified $\alpha \kappa \rho \alpha \sigma i \alpha$ and to be the least blameworthy example among these. On this reading, the desire for money, profit, winning or honour is a kind of appetitive desire. This interpretation follows Lorenz (n. 34); and C. Natali, 'Nicomachean Ethics VII.5-6: beastliness, irascibility, akrasia', in id. (ed.), Aristotle's Nicomachean Ethics, Book VII. Symposium Aristotelicum (Oxford, 2009), 103-29. However, my reading of the Poetics does not presuppose a specific stand on this issue. 
Furthermore, Aristotle considers temper and irritability to be more natural than excessive and unnecessary appetites (Eth. Nic. 1149b6-8). This affects the blameworthiness of $\dot{\alpha} \kappa \rho \alpha \sigma i \alpha$ triggered by temper, because it is more pardonable to follow natural desires common to everyone (Eth. Nic. 1149b4-6). In such cases we feel forbearance

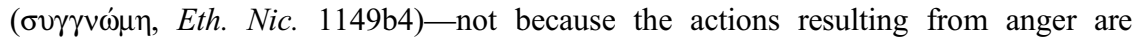
involuntary, but because they reflect pardonable lapses in human nature. While our temper may occasionally mislead us, it is nevertheless appropriate for us as human beings to have it. There are, then, at least three reasons for considering $\dot{\alpha} \kappa \rho \alpha \sigma i \alpha$ triggered by temper as less blameworthy than other types of $\dot{\alpha} \kappa \rho \alpha \sigma i \alpha$ : (i) temper somehow follows reason and reacts to unjust or offensive behaviour; (ii) acting from anger is not done with pleasure but out of distress; and (iii) it is more pardonable to follow natural desires than striving for excessive and unnecessary appetites.

Let us sum up so far. Qualified $\dot{\alpha} \kappa \rho \alpha \sigma i \alpha$ covers a variety of cases. It may involve being blinded by a desire for fine and excellent objects that are choiceworthy in themselves; and it may involve being blinded by temper. Given the fine-grained nuances when it comes to the blameworthiness of these cases, being blinded by temper might very well emerge as the most attractive candidate for $\dot{\alpha} \mu \alpha \rho \tau i \alpha$ in Poetics 13: it is more pardonable ( $\mu \hat{\alpha} \lambda \lambda \mathrm{ov} \sigma v \gamma \gamma v \omega \dot{\mu} \eta$, Eth. Nic. 1149b4) than any sort of $\alpha \kappa \rho \alpha \sigma i \alpha$ triggered by appetite and is the least blameworthy subtype. As I shall argue in subsection $c$, this type of qualified $\dot{\alpha} \kappa \rho \alpha \sigma i \alpha$ moreover allows us to understand Oedipus' downfall. That, however, does not mean that weaknesses of will triggered by fine and excellent objects does not qualify as $\dot{\alpha} \mu \alpha \rho \tau i \alpha$ as per Poetics 13 . It certainly does, since all types of qualified weakness of will fulfil the decisive criterion: they do not justify us attributing any degree of badness or vice ( $\alpha \kappa i \alpha)$ to the agent but are only examples of $\dot{\alpha} \mu \alpha \rho \tau i \alpha$. Speaking differently, none of them is serious enough to be juxtaposed with 'proper' $\alpha \kappa \rho \alpha \sigma i \alpha$, which regards necessary bodily needs such as eating, drinking and sex.

The failure of the akratic agent is further better understood in light of Aristotle's distinction between impetuosity ( $\pi \rho 0 \pi \varepsilon \dot{\varepsilon} \varepsilon 1 \alpha)$ and weakness ( $\alpha \sigma \theta \dot{v} v \varepsilon 1 \alpha)$ when discussing $\dot{\alpha} \kappa \rho \alpha \sigma i \alpha$. While the weak type deliberates and later abandons the result of his deliberation owing to his feeling, the impetuous is led on by feelings and does not deliberate (Eth. Nic. 1150b19-22). The impetuous type fills out the picture of $\dot{\alpha} \mu \alpha \rho \tau i \alpha$ perfectly: desire makes him jump to conclusions before deliberating and he does not realize the true consequences of his actions before it is too late. He is, in truth, blinded either by his temper or by a pursuit for fine objects and overlooks particular facts he would have grasped if he deliberated enough.

If this interpretation is right, one might ask: how are we, more specifically, to explain the ignorance of the protagonist who is led astray by a $\alpha \mu \alpha \rho \tau i \alpha$ ? On my interpretation, the reasoning of the weak-willed agent is influenced by desire so that he acts in ignorance of particular facts. But that $\dot{\alpha} \mu \alpha \rho \tau i \alpha$ is connected to ignorance of particulars, as we have seen, is already an essential feature of the reading of $\dot{\alpha} \mu \alpha \rho \tau i \alpha$ as an 'excusable ignorance'-so what is really the disagreement here? The crucial difference is as follows: the critics who see $\dot{\alpha} \mu \alpha \rho \tau i \alpha$ as linked with excusable ignorance insist that the ignorance of particulars is not due to the character of the agent but to external circumstances. Consequently, the $\dot{\alpha} \mu \alpha \rho \tau i \alpha$ is considered involuntary and a kind of ignorance for which one cannot be held morally responsible. The reading I am now defending, in contrast, purports that one misses the particular(s) owing to a moral weakness, namely qualified $\dot{\alpha} \kappa \rho \alpha \sigma i \alpha$, which is triggered by temper or by the desire for fine, good and choiceworthy things. This interpretation explains why the protagonist 
is not morally pre-eminent: rather than suffering owing to an involuntary lack of information, the tragic hero is blinded when it comes to perceiving a few, but still essential, particular facts. This blinding is caused by nothing other than $\dot{\alpha} \mu \alpha \rho \tau i \alpha$ itself: a hasty temper or weak spot for fine, excellent and desirable things. $\alpha \mu \alpha \rho \tau i \alpha$ then ends up as being a serious ( $\mu \varepsilon \gamma \alpha \dot{\alpha} \lambda \eta)$ flaw, since the disposition the hero has to be guided by desire rather than by reason ends with a devastating outcome. But this does not make the protagonist a bad person; for $\dot{\alpha} \kappa \rho \alpha \sigma i \alpha$ does not justify calling someone evil

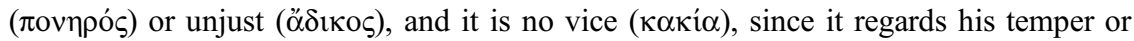
his pursuit for fine, good and desirable things. The aim of his rational choice is normally

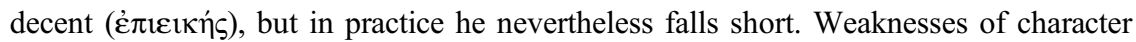
that fall into the category of qualified $\dot{\alpha} \kappa \rho \alpha \sigma^{\prime} \alpha$ are therefore particularly suitable for the undeserved misfortune in tragedy. To paraphrase Aristotle's point in Eth. Nic. 1151a10, weak-willed people are not bad persons - they just do bad things.

\section{c. Oedipus-blinded by temper}

So far I have argued for my interpretation on grounds of Aristotle's philosophy. It is now time to explore its potential for interpreting the development of the plot in his favourite tragedy, Sophocles' Oedipus Tyrannus. ${ }^{39}$ As I will illustrate in what follows, Oedipus has a flaw that makes him act in ignorance of particular facts, namely his temper.

An interpretation of $\dot{\alpha} \mu \alpha \rho \tau i \alpha$ as weakness of will triggered by temper provides us with a good explanatory model of the downfall of Oedipus: at the point of time when Oedipus meets Laius on the road, Oedipus has already been informed by the oracle that he will murder his father. In Corinth he was also confronted with the question of whether Polybus and Merope were his birth parents, and it was this question that brought Oedipus to the oracle in the first place. When Oedipus comes into a quarrel with Laius, he already knows (i) that he is predicted to murder his father, and (ii) that Polybus might not be his biological father. Still, he kills a group of unknown men, including Laius, when angry ( $\delta \mathrm{r}^{\prime}$ ó $\rho \gamma \eta \bar{\varsigma}, O T$ 807). The murder of Laius is indeed no result of unprovoked aggression, but nevertheless seems to be a hasty reaction. As Oedipus himself points out, Laius first offended him by trying to drive him from the road by force (OT 804-5). If Oedipus had thought carefully and undisturbed through the matter, however, he would be able to realize that he should refrain from killing any man old enough to be his father if he was to be completely sure not to fulfil the foretelling. Although killing someone who acts as one's enemy was not blameworthy according to Greek customs to begin with, ${ }^{40}$ Oedipus now renders it possible for the prophecy to come true. Oedipus never intends to do wrong, but still ends up committing patricide, in spite of being no true wrongdoer. Since he possesses the knowledge needed for not killing his father, the anger of Oedipus apparently makes his reason overlook the crucial particular premises, and for a brief moment on the road he acts because of his

39 E. Schütrumpf, 'Traditional elements in the concept of hamartia in Aristotle's Poetics', HSPh 92 (1989), 137-56, at 154 argues that Oedipus acts involuntarily on the basis of Oedipus at Colonus (=

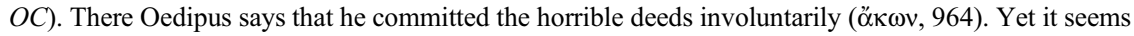
too hasty to draw such a conclusion. While it is true that $O C$ portrays Oedipus as having acted involuntarily, it would be problematic to expect Aristotle to use one play $(O C)$ to interpret another $(O T)$.

${ }^{40}$ E.g. Finglass (n. 28), 73 writes that Oedipus 'could have expected to be acquitted from an Athenian court'. 
temper. Later, when the prophet Tiresias tells him that he has murdered his father (OT 354-65), he responds by accusing him of being paid by Creon to undermine his position as the king of Thebes (OT 380-403), and shortly afterwards Oedipus desires Creon's death (OT 623). This incident clearly shows that Oedipus has an anger that occasionally gets out of hand, since he now rejects a conclusion that is in harmony with the particular facts he already knew. ${ }^{41}$

Furthermore, it would be imprecise to link the specific $\dot{\alpha} \mu \alpha \rho \tau i \alpha$ of Oedipus only with the incident at the road (or with the accusation of Tiresias, for that matter). First of all: since Oedipus' hastiness affects the structure of the plot at different points of time, these incidents cannot be taken as the $\dot{\alpha} \mu \alpha \rho \tau i \alpha$ itself-if so, the plot would end up with several $\dot{\alpha} \mu \alpha \rho \tau i \alpha 1$. Rather, it seems like the weakness itself causes the problems. This leads towards an understanding of $\dot{\alpha} \mu \alpha \rho \tau i \alpha$ as a feature inherent in the agent, rather than as one specific action or one particular point of the plot. ${ }^{42}$

In short, qualified $\dot{\alpha} \kappa \rho \alpha \sigma i \alpha$ provides us with an explanation of $\dot{\alpha} \mu \alpha \rho \tau i \alpha$ as a moral weakness that plays a causal role in the tragic plot. The reading of $\dot{\alpha} \mu \alpha \rho \tau i \alpha$ that I have carved out gives us a good understanding of why the tragic protagonist must be a middle character: the akratic hero does not qualify as morally outstanding, since he has a weakness connected to his temper or to his desire for fine, good and choiceworthy things. The weakness is at the same time not so serious that it renders the hero vicious,

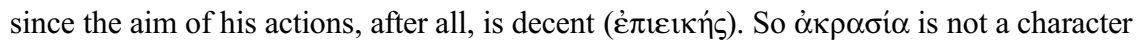
trait that can be equated with vice. Instead, the akratic person falls short for a short moment merely because he has a disposition to abandon reason. The akratic hero will therefore realize his miscalculation after the action is carried out and be filled with regret ( $\mu \varepsilon \tau \alpha \mu \varepsilon \lambda \eta \tau \iota \kappa o ́ \varsigma)$.

\section{HAMARTIA REDEFINED}

It is now time to spell out the redefinition: $\dot{\alpha} \mu \alpha \rho \tau i \alpha$ is a weakness in the tragic hero's moral character that gives him a tendency to make mistakes $(\dot{\alpha} \mu \alpha \rho \tau \eta \dot{\eta} \mu \alpha \alpha)$ when acting. This weakness is $\dot{\alpha} \kappa \rho \alpha \sigma i \alpha$ in a qualified sense, which is triggered either by temper or by a pursuit for excellent, fine and desirable things.

41 There is also another instrument that contributes to Oedipus' downfall: the divine influence of Apollo. It is Apollo's oracle that informs Oedipus of his destiny; it is Apollo who sends the plague to Thebes; and it is Apollo who requires the death or exile of Laius' murderer; cf. S. Lawrence, Moral Awareness in Greek Tragedy (Oxford, 2013), 42-5, 140-7; and D. Kovacs, 'On not misunderstanding Oedipus Tyrannos', CQ 69 (2019), 107-18. A possible problem arises here, since Aristotle rejects any decisive divine influence (1454a37-b6). He holds that there should be nothing irrational in the events and, if there is, it should lie outside the play (1454b6-8). Although Aristotle often gives Sophocles' Oedipus as an example, I believe we should be careful of interpreting these elements as reflecting Poetics 13. For a discussion of divine action in OT, cf. D. Cairns, 'Divine and human action in Sophocles' Oedipus Tyrannus', in id. (ed.), Tragedy and Archaic Greek Thought (Swansea, 2013), $119-71$.

${ }^{42} \mathrm{I}$ am here drawing on Manns (n. 11) and Ostwald (n. 14), both of whom distinguish between $\dot{\alpha} \mu \alpha \rho \tau i \alpha$ and $\dot{\alpha} \mu \alpha \rho \tau \eta \mu \alpha$. Manns's argument is as follows: in ancient Greek, in general, there exists a difference between the suffixes $-i \alpha$ and $-\mu \alpha$. While nouns that end with $-i \alpha$ normally signify abstracts, nouns that end with $-\mu \alpha$ usually denote concretes and refer to the result of an action (nomina rei actae); cf. E. Bornemann and E. Risch, Griechische Grammatik (Frankfurt am Main, 1978 ${ }^{2}$ ), 310, 312; E. Schwyzer, Griechische Grammatik (München, 1953), 1.468-9, 1.522-4. Other examples are

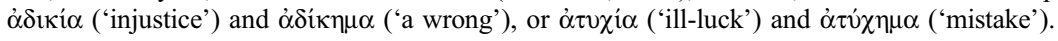


My account of $\dot{\alpha} \mu \alpha \rho \tau i \alpha$ entails that the most beautiful tragic plot is a plot in which the protagonist himself is morally responsible for his own downfall to a certain degree. What 'to a certain degree' means is decided by Aristotle when he rules out the figures

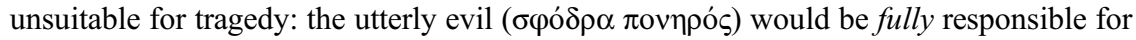
the change from good to bad fortune, and hence he would deserve the suffering that

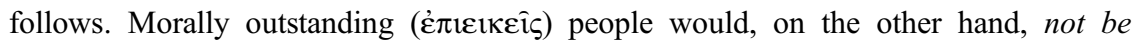
responsible at all for their misery and evidently not deserve a bad fortune. The tragic hero, who is a middle character ( $\dot{o} \mu \varepsilon \tau \alpha \xi v^{\prime}$ ), is located between these: he does not deserve his misfortune, since the seriousness of his $\dot{\alpha} \mu \alpha \rho \tau i \alpha$ does not harmonize with the tragic outcome. This conclusion should, then, under no circumstances be taken as a justification of his misfortune-for the tragic hero certainly does not deserve misery. It states only that he is something more than a victim who suffers owing to incidental circumstances.

University of Oslo

HILDE VINJE

hilde.vinje@ifikk.uio.no 